\title{
Bridging Global Boundaries for IS Project Success
}

\author{
William DeLone \\ American University \\ wdelone@american.edu
}

\author{
Gwanhoo Lee \\ American University \\ glee@american.edu
}

\begin{abstract}
Despite the increasing attention to global IS work, there is limited understanding of why and how global IS development projects succeed or fail. Based on the literature on IS success and global teams, we develop a conceptual framework for global IS development project success. We also conducted interviews with nine global IS project managers to validate this framework through a qualitative attribution analysis to identify common themes and patterns of the interview results. Global project managers identified time separation, cultural differences and geographic distance as the most significant barriers to project success. Organizations implemented various communication mechanisms, task programming, and project control methods to mitigate global risks, leading to project success.
\end{abstract}

\section{Introduction}

IS development projects increasingly involve global teams as organizations try to make the most of their resources. In addition to domestic employees, IS development project often include employees and/or outsourcing vendors from other countries, which increases the complexities and risks associated with these projects. Certain factors inherent in "global" contexts often represent barriers that make it difficult to communicate, coordinate and exchange task information. A key challenge for IS organizations today is to make their global IS project teams work effectively and deliver quality systems on time and on budget.

Despite the increasing attention to global IS work, we have very limited understanding of why and how global IS development projects succeed or fail. Research in geographically distributed and virtual teams has helped us understand how teams can be more effective when working globally, but most of this work does not address the complexities of working across organizational, cultural and other global context boundaries. Similarly, research in IS project success has helped understand how to model and investigate IS success factors, but very little empirical work in this area has focused on global IS work. Our research is designed to make a unique contribution to the IS literature by drawing on these different bodies of literature to formulate and empirically test a framework for global IS development project success.
Our research recognizes that global IS project teams are separated by multiple boundaries (e.g., distance, time, culture, organizational), which makes their work more difficult, thus reducing the likelihood of success. These boundaries and other exogenous variables (e.g., nature of the task, prior work experience) constitute "situational variables," which affect a global IS project's potential to succeed. At the same time, global IS projects succeed when certain mediating processes (e.g., communication, coordination, sharing knowledge, building trust) aim at reducing the negative effects of situational variables. Our two research questions are, therefore: How do global situational variables affect the likelihood of global IS development project success? And, which mediating process variables increase the chance of success, given the presence of these situational variables?

This study investigates these questions empirically based on nine interviews with global IS project managers. We first present our theoretical foundations and propose a research framework. In the following sections we discuss our methodology, results and conclusions.

\section{Theoretical Framework}

Communication technologies make it easy for teams to work together when their members are separated by time, distance or other dividing characteristics, particularly for teams working on IS projects [1]. But these boundaries bring about substantial challenges. Team boundaries can be thought of as dividing lines, "edges" or "discontinuities" that team members need to bridge to collaborate with each other (e.g., geography, time zones, functional expertise). Field research studies generally focus on just one or two boundaries, often ignoring other important boundaries [2,3]. Therefore, we still do not completely understand the factors that may lead to success when work needs to be done across these boundaries.

Since we are interested in IS projects, which are carried out by implementation teams, our research framework follows the typical "input-process-outcome" (I-P-O) model widely used to study group effectiveness [4]. The inputs in our model are situational variables that represent the context in which global IS project teams operate. The process variables represent what the team does to carry out a global IS project. The output variables represent IS project success outcomes. 
In the next section we discuss our dependent variable, global IS project success. In the following section we discuss the situational variables and how they affect global IS project success. These situational variables include global team boundaries and other variables related to the task context. In the next section we discuss process variables, how they are affected by situational variables, and how they in turn affect IS project success. We then use these theoretical arguments to formulate a more elaborated version of our research framework (Figure 1).

\subsection{Outcomes: Global IS Project Success}

IS project success is a multi-dimensional variable. No single measure alone can sufficiently tap into various dimensions of IS project success. The research literature suggests that IS project performance consists of two major dimensions: process performance and product performance [5]. Process performance refers to how well the IS project process has been undertaken. It is measured by on-time/on-budget completion of the project, communication effectiveness between IS staff and users, user participation, etc. [6].

On the other hand, product performance refers to the performance of the information system delivered by the project to end-users. According to the DeLone and McLean's updated IS Success Model [7], IS success is measured by the following dimensions: system quality, information quality, service quality, system use, user satisfaction and system net benefits. Based on these studies we have identified the following measures of IS project success for our research study: on-time completion, within-budget completion, costs/effort, meeting system requirements, system quality, user satisfaction, system use, and net system benefits.

\subsection{Inputs: Situational Variables}

Geographic Distance Boundaries. Studies on distributed IS teams generally associate geographic separation with increased coordination challenges, more delays, communication problems, difficulties to relate to contextual information, and differences in feedback cycles [8-10]. Armstrong and Cole [11] also found that geographic distance led to misunderstandings and conflict escalation.

Time Boundaries. Global collaborators are often separated by time because of differences in working hours, time zones, and/or working cycles that reduce the overlapping work time available for synchronous interaction [2, 12], which make it more difficult to communicate and coordinate. Furthermore, global team members often face different temporal pressures coming from various corporate schedules and priorities and different communication technologies, challenging team members to manage the timing of their activities effectively [12].

Organizational Boundaries. Recent trends in popular work arrangements like outsourcing are leading to an increase in the utilization of groups that cross organizational boundaries [13, 14]. Research on distributed work groups often includes teams that have members from multiple organizations $[11,15]$. Differences in organizational affiliations can reduce shared understanding of context and inhibit a group's ability to develop a shared sense of identity. Similarly, while one of the key drivers of IT outsourcing is cost reduction, outsourcing involves substantial hidden costs [16].

Functional Boundaries. Some of the problems of global work have to do with functional differences that may exist between sites [17]. Research suggests that functional differences can influence team processes, which in turn can affect the group's performance $[18,19]$.

Cultural Differences. Cultural differences can make collaboration and communication more difficult $[1,3]$. Studies of global software teams have acknowledged that factors like cultural differences play a role [20]. Cultural difference among global team members also impedes the development of trust [21]. If the team members do not have similar cultures, their relationship may create divergent values that make it difficult for them to trust one another and provide a fundamental cause to destroy the relationships [22].

Language differences. Language differences can make

\begin{tabular}{|c|c|c|}
\hline Situational Variables & Process Variables & Outcome Variables \\
\hline $\begin{array}{l}\text { Team Boundaries } \\
-\quad \text { Geographic distance } \\
-\quad \text { Time separation } \\
\text { - } \quad \text { Multiple organizations } \\
\text { - } \quad \text { Cunctional differences } \\
\text { - } \quad \text { Language differences } \\
\text { Other Context Variables } \\
\text { - Task context } \\
\text { - } \quad \text { Grior experience with team } \\
\text { - }\end{array}$ & $\begin{array}{l}\text { Coordination } \\
-\quad \text { Communication } \\
\text { Task Programming } \\
\text { Team Cognition } \\
-\quad \text { Shared Knowledge } \\
-\quad \text { Shared Beliefs } \\
-\quad \text { Developing Trust } \\
\text { Other } \\
-\quad \text { Use of Technology } \\
-\quad \text { Project Controls }\end{array}$ & $\begin{array}{ll}\text { IS } & \text { Project Success } \\
- & \text { On time } \\
- & \text { On budget } \\
\text { - } & \text { Cost/effort } \\
- & \text { System quality } \\
\text { - } & \text { User satisfaction } \\
\text { - } & \text { Meeting requirements } \\
\text { - } & \text { System use } \\
\quad \text { Net system benefits }\end{array}$ \\
\hline
\end{tabular}

Figure 1: Research framework for IS project success 
communication among project team members difficult and ineffective, thus negatively affecting project performance.

Other Context Variables. While the main focus of our study is in global context variables, there are other context variables that may affect the effectiveness of global collaboration. Therefore, we include other context variables that may affect team outcomes, including: task context [4], prior work experience with team members [23], and prior global work experience.

\subsection{Process Variables}

Coordination. Coordination is "the effective management of dependencies among task activities" [24]. When task activities contain multiple dependencies, as in the case of global IS projects, they need to be tightly coordinated. But it is very difficult to coordinate tasks when team members are separated by multiple boundaries. Research studies have found empirical evidence about the importance of coordination for IS work $[25,26]$, particularly when the work is done globally [2].

March and Simon [27] suggest in the classic organizational literature that teams manage these dependencies via two general types of coordination mechanisms: task programming and team communication. They argued that coordination of repetitive and routine aspects of the task can be "programmed" using mechanisms like tools, schedules, plans, division of labor and specifications. However, task programming mechanisms are less effective for aspects of the task that are uncertain because dependencies can no longer be managed in a programmed way, which makes teams resort to communication (i.e., "coordination by feedback") in these cases.

Team Cognition. Team cognition mechanisms like shared knowledge and shared beliefs enable members to form accurate explanations and expectations about the task and about team members' actions, which helps them plan for their own actions $[28,29]$. Team cognition is particularly important for IS project success when the project context makes it difficult to employ traditional coordination mechanisms like direct communication. When collaborators are in close proximity, it is easier for them to coordinate things informally because they can meet frequently and spontaneously $[25,30]$. Team cognition can be a great complement to traditional coordination mechanisms because it helps teams coordinate implicitly by enabling team members to synchronize their actions based on expectations about what others in the group are likely to do. This study explores three types of team cognition mechanisms: shared knowledge, shared beliefs and trust.

Shared knowledge provides a common knowledge base through which team interaction can occur, which enables team members to tap into expert knowledge sources in the team [31]. Studies have shown the positive effect of shared knowledge in IS project outcomes [20, 32].

Because team members can have shared mental representation of other things besides knowledge, we use the term shared beliefs to refer to the different mental schemas and views that team members may share. Team members may share views about many things like goals, strategies, individual capabilities, and task priorities, which research has shown to be important for performance [28].

Trust is "the willingness of a party to be vulnerable to the actions of another party based on the expectation that the other will perform a particular action" [33], which reduces transaction costs $[34,35]$ and facilitates information exchange [36]. Trust is particularly important in the context of global IS projects where a temporary global team is assembled on an as-needed basis [37]. Trust prevents geographical distance from leading to psychological distance [38]. However, the global context constrains the development of trust because factors known to contribute to social control and coordination, such as geographical proximity, similarity in backgrounds, and experience, are often absent in the global context $[39,40]$.

Other Process Variables. We also investigate two process variables that can have an effect on IS project success: use of technology and project controls. The interaction of team members that are separated by multiple boundaries, particularly geographic distance and time, is largely mediated by information technologies, which can affect how teams use information technologies, which can in turn affect outcome variables [4]. Also, because of the difficulty of managing and controlling IS projects when team members are separated by multiple boundaries, teams may need to implement project controls that are more suitable for these contexts, and the effectiveness of these project controls can have a substantial impact on IS project outcomes.

\section{Research Methodology}

\subsection{Sample}

We conducted nine face-to-face and telephone, semistructured interviews with managers of global IS projects in five companies. Interview questions focused on the relationships between global situational factors and project performance and on the project processes employed to mitigate the potential negative impacts of global situational factors. Interviewees were located in the India, Ireland, South Africa and the United States. Four of the nine IS projects had been completed, four were nearing completion and one project was mid-way through a five year development schedule. Six projects involved one to three outsourcing partners and the three other 
projects were globally insourced. The projects involved two to seven development sites including Australia, Canada, India, Ireland, South Africa, and the United States. Six projects reported project budgets ranging from $\$ 500,000$ to $\$ 45$ Million and two additional projects reported scope in terms of 6,100 and 13,600 person-hours.

\subsection{Data Collection and Analysis}

The primary research method we used in this research is qualitative analysis with attributional coding. An attribution is defined as a statement made by a participant that links two variables in a "cause-effect" relationship [42]. All interviews were audio taped. Interviews took approximately one hour and were taped with prior consent from the participant. Most of the questions were framed to uncover one of three types of attributions: situational variables cause outcomes (SO), situational variables affect team processes (SP) and team processes affect outcomes (PO). Participants were first asked questions intended to generate attributions about the general effect of situational variables on specific success outcomes $(\mathrm{SO})$, without tying these answers to specific projects. Then, participants were asked to identify a recent important global IS project in which they participated and all remaining questions were asked in reference to that specific project. These questions were framed to generate attributions about how situational variables affected process variables (SP) (i.e., how they managed and coordinated the project) and what was the effect of these process variables on project outcomes (PO).

The interviews were transcribed verbatim into text documents by research assistants. The researchers then coded the text using a template with hierarchical codes to differentiate the different types of attributions made by participants [41]. The hierarchical coding scheme was defined with two primary high-order codes and one valence dimension. The first main code category was created for general attributions [42] of the effect of one type of variable over another. The second code category identified the specific variable involved. For example, a code of "S.D-O.T" means that the situational variable (S) geographic distance (D) was attributed as affecting the success outcome variable $(\mathrm{O})$ on-time delivery $(\mathrm{T})$. The valence dimension was coded to specify the direction and strength of the success outcome as $\mathrm{P}, \mathrm{N}$ and 0 for positive, negative and no effect.

The first two interviews were coded independently by two or three of the researchers. After the first interview was coded, the three researchers met to analyze the coding. All differences were discussed and resolved by consensus. After some discussion, there were no disagreements on the final consensus coding. After the second interview was coded, the three researchers met again to compare their coding. Again all differences were again discussed and resolved by consensus. Since there were no disagreements in the interpretation and coding of attributions in the text, but rather inconsistency in identifying attributions, coding reliability was measured as agreement between each research coder's initial coding and the final consensus coding. The average reliability for the two coded interviews was $64.8 \%$ measured as the number of agreements over agreements plus disagreements [43] and a Kappa reliability of 62.6\% [44]. Since the three researchers achieved an acceptable kappa level over $40 \%$ [45], the remaining interviews were coded individually by all three researchers.

Once the transcripts were coded, the coded attributions along with relevant interview text were extracted and entered into a database. Each and every text passage and code extracted was discussed and interpreted jointly by all researchers. In cases of lack of consensus among the authors, the codes were corrected accordingly. Only 5 of the 280 attributions recorded were changed because of mistakes, more than disagreements. The final interview text contained approximately 120 pages and 62,000 words, which generated a total of 280 , or an average of 31.1 attributions per interview. Of these, 88 were SO attributions, 131 were SP, and 61 were $\mathrm{PO}$ attributions.

\section{Results}

\subsection{Outcomes: Global IS Project Success}

Project managers applied a variety of metrics in making their success assessments (Table 1).

Table 1: Frequency of project success measures

\begin{tabular}{|l|c|}
\hline \multicolumn{1}{|c|}{ Success Measure } & Number of Projects \\
\hline System quality & 9 \\
\hline On time delivery & 8 \\
\hline Delivered within budget & 5 \\
\hline User satisfaction & 5 \\
\hline Meeting requirements & 3 \\
\hline System use & 2 \\
\hline Net benefits & 1 \\
\hline
\end{tabular}

Project quality and on-time delivery were success metrics mentioned in nearly all projects. Other success measures were affected by the nature and phase of the project. For example, system use and net benefits were mentioned only for systems that had been in use for a year or more. Business value was mentioned as the most important measure for a strategic system that had been in use for over a year. Several project managers indicated that budgets had to be revised at least once during a project to account for the additional effort needed to make global projects succeed despite global barriers. One project manager estimated that budgeted resources and timelines should be multiplied by a factor of 1.5 for global (vs. domestic) projects. In two cases, project success was also measured by recognition. One project received a $\mathrm{CIO}$ award for performance. Another project "was 
showcased as a model for offshore projects [in its organization]."

\subsection{Attributions Involving Situational Variables}

This section discusses the impacts attributed to situational variables in terms of their effects on project outcomes and on process variables.

Geographic Distance. Four respondents indicated that distance was not a factor, while the other five mentioned that distance had negative effects. Comments ranged from "I didn't see it [distance] as a problem" to "a major barrier that has a negative impact" and "part of the reason the project wasn't working so well is that everybody was working remotely." However, when one investigates the specifics of these comments, one can see that reducing or eliminating the impact of geographic dispersion comes at a substantial cost because teams invested significant effort and resources to overcome the difficulties of working over distance barriers. For example, one participant indicated that "2 people can solve a problem on the phone, but it is going to take them 3 times as long to do it as if they were sitting in the same room".

In fact, such increases in the level of effort have a negative impact on the project productivity and costs. As one participant commented, "[the project] required frequent travel and one of the impacts was that we had a significant budget for travel in the project financials." People often travel to other sites because this improves communication, knowledge sharing, productivity, and issue resolution. One participant characterized this as "reducing the psychological distance" among team members, meaning that when team members travel to each others' project sites and develop familiarity with teammates and their work contexts, the perceived distance is much smaller. But this is costly and time consuming.

Geographically dispersed collaborators also put more effort and rigor into processes and formal documents. Six participants indicated that geographic distance made them adopt practices to improve team communication and three indicated the need for special project controls. Additional efforts included: creating redundant, counterpart positions; frequent, regularly scheduled video or teleconferences; asking members other sites for written interpretations of the documents (what they call "understanding documents"); rotation plans to other sites; tighter project management controls; and heavy reliance on technology and tools.

Time Separation. This is an interesting situational variable in that time differences are often used advantageously so that some team members are advancing the work in one site during other members' off-work hours. However, this requires close attention to timing, detailed definition of tasks and tight coordination of activities. When the timing of work is difficult to plan and synchronize (e.g., unplanned interactions, uncertain task dependencies, tight deadlines), then time separation becomes a substantial collaboration barrier and often results in time delays.

A number of factors affect the difficulty of working across time zones, including: whether time differences are aligned with workflows (i.e., work is handed by one site at the end of their work day, over to another site whose work day is just starting); the number and variance of different time zones represented in a team (e.g., working across two time zones is much easier than working across multiple time zones); and overlapping work hours and the magnitude of the time difference. For example, one participant commented, "we only had a two-hour time window to work together .... a task that should take two or three weeks might take a month or two". An important consequence of time separation is that collaborators need to make conscious choices about the timing and mode of interaction (i.e., communicate asynchronously during non-overlapping hours or wait until overlapping hours to communicate synchronously).

Time differences also bring about a substantial burden in the time demands and personal lives of team members. One participant commented that the way they addressed problems of time difference was by being available 24 hours a day to their teams through pagers, mobile phones and other wireless devices. The benefits of spontaneous team interaction in teams without coordinating practices are severely limited with time separation.

Organizational Boundaries. Interestingly, only one participant attributed a negative impact from outsourcing. This was partly because organizations were maturing in their work experience with subcontractors and vendors. "We don't find this [i.e., multiple companies] as a problem because we ensured that we worked like one team," said a participant from a multilateral government organization. In some cases, working with multiple organizations is viewed as an advantage because multiple companies may reduce project risks and create competition, leading to better project performance.

The external organizational boundaries did have significant impacts on process variables such as project control mechanisms. For example, client companies needed tighter control mechanisms to prevent outsource partners from opportunistic behavior. Multiple companies had to establish agreed-upon procedures, processes, and quality standards early in their project lifecycle. The presence of multiple companies also affect the way work was coordinated. For example, organizations sent team leaders to their partner organizations and made them fully responsible for work in their partner organization.

Functional Differences. Functional differences were only found to impact project success in two interviews. In both cases the lack of business knowledge among the developers was seen as having a negative influence on system quality and coding time. This functional boundary inhibited knowledge sharing and common understanding. 
In one project this problem was handled by funneling all communications through the project manager to reduce misunderstandings.

Cultural Differences. Cultural differences were attributed to project outcomes in six interviews. "Our UK staff and the US staff have a different way of looking at the world which makes things difficult," said one participant in one interview. In general, cultural differences had negative effects on project performance. It caused time overruns, budget overruns, high costs, and low system quality. Culture differences were particularly salient in the initial phase of projects. In particular, differences between Asian culture and Western culture hindered project success. "They [our Asian partners] are very reluctant to let you know if something is not going to schedule ... they feel that if they're telling you a problem, it reflects badly on them," said a participant.

However, in some cases, cultural differences were not problematic. Sometimes, partner companies were willing to compromise their culture in order to achieve project success. "We have moved some of the Indian people to South Africa. Keep in mind that we were in a period of Ramadan which was an Indian religious holiday and the people were very good in working in over that period," said a participant from South Africa.

Cultural differences affect process variables such as communications, shared beliefs and trust. First, cultural differences impact the way people communicate. "Within our development teams....people who don't understand things, just pick up the phone and call... However, they [our partner company in India] tend to sit on problems and try to figure out those problems on their own," said a US participant. Organizations used face-to-face meetings to help people understand cultural issues.

Language Differences. Language differences increased project duration and cost in three projects. Even if all team members can speak a common language, non-native speakers usually have difficulties in reading between the lines, thus hindering project performance. According to one project manager, "generally everyone converses in on global programs however, when you're dealing with people who are not native speakers of English, then suddenly the ability to really get across nuances of what's really going on... becomes an issue."

Language differences influence project performance primarily through communication problems. In order to mitigate risks from the language barrier, one organization provided a training program to enhance their employees' language skills.

Task Context. The nature of the development tasks can have an impact. For example in one project an offshore contractor was assigned the most complex and critical system component without having the whole enterprise picture. This resulted in integration problems and delayed deliverables. Other projects avoided this problem by assigning less critical, more structured tasks and tasks with fewer dependencies (e.g., coding, testing) to their offshore contractors and by bringing offshore team leaders onsite for the design phase to ensure a common understanding of the requirements and design.

Prior Work Experience with Team Member. Having prior experience working with each other has a positive effect on global projects outcomes according to three participants. One participant indicated that this was "a very big factor in the project success." Three participants also mentioned that such prior experience helps develop trust in the team. Two participants indicated that their team did not have such experience working together, so they had to spend some time building team relations at the beginning of the project.

Global Project Experience. Global project experience impacted global project success in four projects. Project team members' lack of prior experience with global projects can create a number of problems. "There were a lot of people within my company who had never worked in an offshore environment before and that created a lot of problems for us," said one participant. Prior experience with the global context is important not only at individual level but also at organizational level. "The project was not being successful, which was a reflection of the fact that it [the project] was one of the first true global projects that my company tried to do." Lack of global project experience often leads organizations to make erroneous assumptions, which undermines their ability to deliver their project on time and on budget. Learning how to work in the global context is a key for project success.

\subsection{Attributions involving Process Variables}

This section discusses the impacts attributed to process variables in terms of their impacts on project outcomes.

Coordination: Communication. Communication is perhaps the most important process variable. Eight of the nine participants interviewed specifically mentioned the importance of effective communication for global IS project success. Most of the problems created by the situational variables relate in one way or another to communication. While some situational variables like distance, time separation and cultural differences make it difficult for teams to communicate, effective teams implement processes aimed specifically at overcoming communication difficulties (e.g., frequent travel, creating liaison roles in other sites, cultural awareness training, over-detailed formal written documents, etc.). Most participants indicated that there is no substitute for faceto-face communication, particularly for more uncertain aspects of the task, which are difficult to discuss over asynchronous media like electronic mail.

Coordination: Task Programming. While task programming is an important coordination mechanism for the most routine aspects of the task, it is also an important success factor in global collaboration. Task programming 
was associated with positive project outcomes in six of the nine interviews. Task programming can help offset some of the problems that exist when the task context makes communication difficult. Therefore, it is not surprising that global teams often re-arrange their task programming schemes to better suit their global context. The most obvious example is one in which the division of labor among team members is purposely implemented to minimize task dependencies between geographically distant sites.

Team Cognition: Knowledge Sharing. Knowledge sharing is tightly related to team communication. Team members often communicate to share knowledge about their task activities, which may affect the activities of other members. While not many participants discussed issues of shared knowledge, those who did emphasized its positive effects on project outcomes. As one participant commented, "requirements, design, functional specifications, and data structures were done here, but we kept at least somebody from the offshore team .... and this was a success factor." Another participant commented, "knowledge sharing is important and it is imperative for programmers there to understand the business ... we traveled to India to educate them about the specifications".

Team Cognition: Developing Shared Beliefs. Two participants also discussed the importance of shared beliefs for project outcomes. In particular, having a shared understanding of project goals and strategies helps manage expectations.

Team Cognition: Trust. Trust was credited with positive effects on project performance in only two cases. "If you don't trust your team there is no point in collaborating. You have to trust your offshore team to give you their best results. ... and this trust is important," said one participant.

Use of Technology. The use of technology was mentioned in four interviews as a means of facilitating communications where distance and time created communication barriers. Project managers advocated using a wide portfolio of technologies including emails, instant messaging, teleconferencing, videoconferencing, web meetings with shared document capabilities and extranets to improve communication and enhance project performance. Teleconferencing was most often cited as an effective technology-based communication method while e-mail was considered inferior in instances where common understanding was needed. The usefulness of different technologies was found to be dependent on the specific purposes for which they were used. One project manager found instant messaging useful for resolving small problems. Defect/issue tracking tools were also mentioned in one interview as a useful for project management.

Project Controls. Effective project control processes were deemed to affect success in five global IS projects.
Putting project control processes in place helps global project teams to achieve better system quality and ontime/on-budget completion. It was important for project managers to be able to see where they were and how they were doing during their projects. One research participant said, "this person is really responsible for all of our project plans and tracking and for monitoring them. She consolidates the project plans so that she can give me a view of where we are globally." In addition, use of project metrics was considered an important project control mechanism by the project managers we interviewed.

\subsection{Attribution Summary}

Table 2 summarizes the number of attributions that connect situational variables with outcome and process variables. A specific attribution is counted only once per interview. The three situational variables that had the most impact on process and outcomes are time zone differences, cultural differences and geographic distance.

Table 2: Attribution frequencies for situational variables

\begin{tabular}{|l|c|c|}
\hline $\begin{array}{c}\text { Situational } \\
\text { Variable }\end{array}$ & $\begin{array}{c}\text { Impacts } \\
\text { Outcomes }\end{array}$ & $\begin{array}{c}\text { Impacts } \\
\text { Processes }\end{array}$ \\
\hline Time Zone Differences (S.T) & 12 & 16 \\
\hline Cultural Differences (S.C) & 11 & 8 \\
\hline Geographical Distance (S.D) & 9 & 25 \\
\hline Prior Work Experience (S.P) & 6 & 4 \\
\hline Language Differences (S.L) & 5 & 5 \\
\hline Prior Global Experience (S.Ox) & 5 & 2 \\
\hline Functional Differences (S.F) & 4 & 2 \\
\hline Task Context (S.Tc) & 3 & 4 \\
\hline Multiple Divisions (S.Oi) & 2 & 2 \\
\hline Multiple Companies (S.Oe) & 1 & 9 \\
\hline
\end{tabular}

Table 3 summarizes the number of attributions that connect process variables with outcome and situational variables. A specific attribution is counted only once per interview. The three process variables that had the most consistent impact on project outcomes and where most frequently connected to situational variables are communication, task programming and project controls.

Table 3: Attribution frequencies for process variables

\begin{tabular}{|l|c|c|}
\hline \multicolumn{1}{|c|}{$\begin{array}{c}\text { Process } \\
\text { Variable }\end{array}$} & $\begin{array}{c}\text { Impacts } \\
\text { Outcomes }\end{array}$ & $\begin{array}{c}\text { Impacted by } \\
\text { Situational }\end{array}$ \\
\hline Communication (P.Cm) & 17 & 25 \\
\hline Task Programming (P.Tp) & 11 & 20 \\
\hline Project Controls (P.Pc) & 7 & 7 \\
\hline Knowledge Sharing (P.K) & 5 & 5 \\
\hline Sharing Beliefs (P.S) & 4 & 5 \\
\hline Developing Trust (P.T) & 2 & 10 \\
\hline Use of Technology (P.Tc) & 2 & 4 \\
\hline
\end{tabular}

\section{Conclusions}

Our study has limitations. First, the sample is small, consisting of nine interviews. While initial findings and conclusions can be drawn from this sample, more 
interviews would increase validity and credibility of our findings. We are currently conducting more interviews for further investigation. Second, our study is limited to the inherent problems of interview research. We are planning to conduct further quantitative studies to develop a better understanding of the factors leading to global IS project success.

Despite these limitations, our study represents an important contribution to the literature on global IS project teams because it is the first study to investigate the effect of multiple team boundaries and other situational variables on global IS project outcomes and how different processes mediate these effects. This study has uncovered important effects of situational variables on global IS project outcomes and the related mediating effects of process interventions. Our main conclusions of the study are summarized below.

1. The significant situational barriers in global IS projects are time separation, cultural differences and geographic distance (Table 2). The processes that are most frequently deployed to minimize the negative effects of these barriers are communication, task programming and more rigorous project controls (Table 3).

2. Time separation has dual effects. On the one hand, when activities can be well coordinated and synchronized, time separation can be used advantageously. This practice is used in "follow-thesun" IT practices in which work in one site is handed over at the end of their working day to another site where the work day is just beginning [9]. Generally speaking, time separation can work well when tasks are well defined and certain, which is when task programming mechanisms provided effective coordination. On the other hand, time separation becomes a substantial collaboration barrier when the task is less defined and more uncertain, thus requiring interactive and frequent communication.

3. Distance was considered a factor in some cases and not in others. Distance is not really a global variable but a location distribution variable. Furthermore, people have learned to handle geographic distance from their experience not only with global projects but also with domestic projects involving multiple locations. Most problems associated with geographic distance correlate with other global situational variables (e.g., cultural differences, time zones, etc.). Once all these other boundaries are accounted for, distance does not appear to be a major impediment for global collaboration.

4. Many global IS projects succeed because failure is not an option by corporate standards. The aggressive push to meet corporate expectations inspires project managers to implement effective processes that overcome global barriers, resulting in project success.
5. All barriers can be overcome with effective processes suited to the task context, but with additional costs, effort and stress. For example, in time separated contexts with little or no working overlap, teams may implement 24 hour-a-day availability policy. Teams also implement other tactics like: frequent travel; relocation; communication and collaboration tools; extreme attention to detail in documents, requirements, and specifications. All of these additional measures come at additional financial cost and burden on personal lives. In essence, in the I-P-O framework we have outlined, one can distinguish two types of processes. The first are the natural processes that teams use to get the work done. However, many global situational variables like culture and time separation have a negative effect on these natural processes. Therefore, effective teams implement special processes (e.g., regular meetings, frequent travel, detailed specifications, etc.) to overcome deficiencies in the natural processes. It is precisely these additional processes that increase the cost and effort in global IS projects. Therefore, the I-P-O framework can be enhanced (Figure 2).

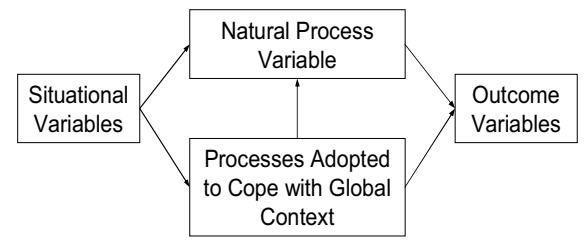

Figure 2: Revised model of global IS project success

6. Communication is the most important and effective coordination mechanism that mitigates negative effects of most situational variables. Communication is particularly effective when tasks are uncertain, ambiguous, unstructured, and less routine. It is critical to establish communication processes and channels in the early stages of a global project.

7. Coordination through task programming was also frequently deployed to mitigate the risks posed by global situational barriers. Task programming is more useful when tasks are certain, unambiguous, structured, and routine. Project managers implemented task programming mechanisms in a way that task dependencies are minimized, communication complexity is reduced, and accountability is increased.

8. Organizations use various technologies to overcome geographical distance and time separation. Importantly, different technologies serve different purposes. Organizations tend to use teleconferencing to work on major issues and problems while they use videoconferencing mainly for socialization. Instant messaging technology is used to sort out small problems that do not require costly teleconferences. There is no single effective technology serving all 
purposes. Instead, a portfolio of technologies collectively addresses various issues and problems of global collaboration.

9. Even though offshore projects appear cheaper, hidden costs make it a less attractive proposition that adds time, effort and costs to projects according to some participants. With the current trends in offshore outsourcing, we were surprised not to hear that global collaboration arrangements were established to reduce costs. Quite the contrary, the consensus is that global collaboration, regardless of outsourcing and offshoring arrangement, adds costs (communication costs, error costs, issue resolutions, etc.).

10. Organizations often struggle in global IS projects, not because of their lack of capability, but because of their lack of awareness of issues, problems, and barriers associated with global work. Once organizations are aware of these global risks, they implement special processes or mechanisms to mitigate them (see Figure 2). Prior experience with global projects plays an important role in increasing organizational awareness of global risks.

11. Global is not such a big word outside of the US in that most other sites are accustomed to working with other countries. U.S. project managers are very accustomed to working across distances and even time zones with collaborators in different states but, their challenges are generally associated with cultural awareness.

\section{References}

[1] W. Orlikowski, "Knowing in Practice: Enacting a Collective Capability in Distributed Organizing," Organization Science, vol. 13, pp. 249-273, 2002.

[2] J. A. Espinosa, J. N. Cummings, J. M. Wilson, and B. M. Pearce, "Team Boundary Issues Across Multiple Global Firms," Journal of Management Information Systems, vol. 19, 2003.

[3] M. B. Watson-Manheim, K. Chudoba, and K. Crowston, "Discontinuities and Continuities: A New Way to Understand Virtual work," Information, Technology and People, vol. 15, pp. 191-209, 2002.

[4] J. McGrath and A. Hollingshead, Groups Interacting With Technology: Sage Publications, 1994.

[5] J. G. Cooprider and J. C. Henderson, "Technology-Process Fit: Perspectives on Achieving Prototyping Effectiveness," Journal of Management Information Systems, vol. 7, pp. 67-87, 1991.

[6] S. R. Nidumolu, "The Effect of Coordination and Uncertainty on Software Project Performance: Residual Performance Risk as an Intervening Variable," Information Systems Research, vol. 6, pp. 191-219, 1995.

[7] W. H. DeLone and E. R. McLean, "The DeLone and McLean Model of Information Systems Success: A Ten-Year Update," Journal of Management Information Systems, vol. 19, pp. 9-30, 2003

[8] J. D. Herbsleb, A. Mockus, T. Finholt, and R. E. Grinter, "Distance, Dependencies and Delay in a Global Collaboration," presented at 2000 ACM Conference on Computer Supported Collaboartive Work, Philadelphia, Pennsylvania, 2000.

[9] E. Carmel, Global Software Teams. Upper Saddle River, NJ: Prentice Hall, 1999.

[10] T. Allen, Managing the Flow of Technology. Cambridge, MA: MIT Press, 1977.

[11] D. J. Armstrong and P. Cole, "Managing Distances and Differences in Geographically Distributed Work Groups," in Distributed Work, P. Hinds and S. Kiesler, Eds. Cambridge, MA: MIT Press, 2002, pp. 187-215.

[12] J. A. Espinosa and E. Carmel, "The Impact of Time Separation on Coordination in Global Software Teams: a Conceptual Foundation," Software Process: Practice and Improvement (forthcoming), 2004.

[13] A. Majchrzak, R. E. Rice, A. Malhotra, and N. King, "Technology Adaptation: The Case of a Computer-Supported Inter-Organizational Virtual Team," MIS Quarterly, vol. 24, pp. 569-600, 2000.

[14] A. Yan and M. R. Louis, "The Migration of Organizational Functions to the Work Unit Level: Buffering, Spanning and Bringing Up Boundaries," Human Relations, vol. 52, pp. 25-47, 1999.

[15] D. Robey, H. Khoo, and C. Powers, "Situated Learning in Cross-Functional Virtual Teams," IEEE Transactions on Professional Communications, vol. 43, pp. 51-66; and Technical Communication, 47 (1) (Joint Special Issue), 2000.

[16] J. Barthelemy, "The Hidden Costs of IT Outsourcing," MIT Sloan Management Review, vol. 42, pp. 60-69, 2001.

[17] D. Ancona and D. Caldwell, "Demography and Design: Predictors of New Product Team Performance," Organization Science, vol. 3, pp. 321-341, 1992.

[18] K. A. Jehn and G. B. Northcraft, "Why Differences Make a Difference: A Field Study of Diversity, Conflict, and Performance in Workgroups," Administrative Science Quarterly, vol. 44, pp. 741-763, 1999.

[19] L. Pelled, K. Eisenhardt, and K. Xin, "Exploring the Black Box: An Analysis of Work Group Diversity, Conflict, and Performance,", Administrative Science Quarterly, vol. 44, pp. 128, 1999

[20] C. D. Cramton, "The Mutual Knowledge Problem and Its Consequences for Dispersed Collaboration," Organization Science, vol. 12, pp. 346-371, 2001.

[21] D. R. Lasher, B. Ives, and S. Jarvenpaa, "USAA-IBM Partnership in Information Technology: Managing the Image Project," MIS Quarterly, vol. 15, pp. 551-565, 1991.

[22] J.-N. Lee and Y.-G. Kim, "Effect of Partnership Quality on IS Outsourcing Success: Conceptual Framework and Empircal Validation," Journal of Management Information Systems, vol. 15, pp. 29-61, 1999.

[23] P. S. Goodman and D. P. Leyden, "Familiarity and Group Productivity," Journal of Applied Psychology, vol. 76, pp. 578586, 1991.

[24] T. Malone and K. Crowston, "The Interdisciplinary Study of Coordination," ACM Computing Surveys, vol. 26, pp. 87-119, 1994.

[25] R. E. Kraut and L. A. Streeter, "Coordination in Software Development," Communications of the ACM, vol. 38, pp. 69-81, 1995. 
[26] K. Crowston and E. E. Kammerer, "Coordination and Collective Mind in Software Requirements Development," IBM Systems Journal, vol. 37, pp. 227-245, 1998.

[27] J. March and H. Simon, Organizations: John Wiley and Sons, 1958.

[28] J. A. Cannon-Bowers and E. Salas, "Reflections on Shared Cognition," Journal of Organizational Behavior, vol. 22, pp. 195-202, 2001.

[29] R. J. Klimoski and S. Mohammed, "Team Mental Model: Construct or Methaphor," Journal of Management, vol. 20, pp. 403-437, 1994.

[30] S. D. Teasley, L. A. Covi, M. S. Krishnan, and J. S. Olson, "Rapid Software Development through Team Collocation"," IEEE Transactions on Software Engineering, vol. 28, pp. 671683, 2002.

[31] M. Alavi and D. E. Leidner, "Knowledge Management and Knowledge Management Systems: Conceptual Foundations and Research Issues," MIS Quarterly, vol. 25, pp. 107-136, 2001.

[32] K. M. Nelson and J. G. Cooprider, "The Contribution of Shared Knowledge to IS Group Performance," MIS Quarterly, vol. 20, pp. 409-432, 1996.

[33] R. C. Mayer, J. H. Davis, and F. D. Schoorman, "An Integrative Model of Organizational Trust," Academy of Management Review, vol. 20, pp. 709-734, 1995.

[34] L. L. Cummings and P. Bromiley, "The Organizational Trust Inventory (OTI): Development and Validation," in Trust in Organizations: Frontiers of Theory and Research, R. M. Kramer and T. R. Tyler, Eds. Thousand Oaks, CA: Sage Publications, 1996, pp. 302-330.

[35] R. M. Kramer and T. R. Tyler, Trust in Organizations: Frontiers of Theory and Research. Thousand Oaks, CA: Sage Publications, 1996.

[36] P. C. Earley, "Trust, Perceived Importance of Praise and Criticism, and Work Performance: An Examination of Feedback in the United States and England," Journal of Management, vol. 12, pp. 457-473, 1986.

[37] S. Jarvenpaa and B. Ives, "The Global Network Organization of the Future: Information Management Opportunites and Challenges," Journal of Management Information Systems, vol. 10, pp. 25-57, 1994.

[38] C. C. Snow, S. A. Snell, and S. C. Davison, "Use Transactional Teams to Globalize Your Company," Organizational Dynamics, vol. 24, pp. 50-67, 1996.

[39] M. O'Hara-Devereaux and B. Johansen, Global Work: Bridging Distance, Culture, and Time. San Francisco: JosseyBass, 1994.

[40] C. Handy, "Trust and the Virtual Organization," Harvard Business Review, vol. 73, pp. 40-50, 1995.

[41] N. King, "Template Analysis," in Qualitative Methods and Analysis in Organizational Research, G. Symon and C. Cassell, Eds. Thousand Oaks: Sage Publications, 1998, pp. 118-134.

[42] J. Silvester, "Attributional Coding," in Qualitative Methods and Analysis in Organizational Research, G. Symon and C. Cassell, Eds. Thousand Oaks: Sage Publications, 1998, pp. 7393.

[43] M. B. Miles and A. M. Huberman, Qualitative Data Analysis: An Expanded Sourcebook. Beverly Hills: Sage Publications, 1994.
[44] J. Cohen, "A Coefficient of Agreement for Nominal Scales," Educational and Psychological Measurement, vol. 20, pp. 37-46, 1960.

[45] R. J. Landis and G. G. Koch, "The Measurement of Observer Agreement for Categorical Data," Biometrics, vol. 22, pp. 159-174, 1977. 